\title{
Effects of Combined Teleconnection Patterns on the East Asian Summer Monsoon Circulation: Remote Forcing from Low- and High-Latitude Regions
}

\author{
Takuya OGASAWARA ${ }^{1}$ \\ Graduate School of Science and Engineering for Education, University of Toyama, Toyama, Japan \\ and \\ Ryuichi KAWAMURA
}

Section of Earth and Environmental Systems, Graduate School of Science and Engineering for Research, University of Toyama, Toyama, Japan

(Manuscript received 6 July 2007, in final form 25 April 2008)

\begin{abstract}
Using the European Center for Medium-Range Weather Forecasts (ECMWF) reanalysis (ERA-40) data, we examined two summertime teleconnection patterns, the Europe-Japan (EJ) and the Pacific-Japan (PJ) patterns, which prevail over northern Eurasia and the western North Pacific, respectively, and highlighted the effects of the combination of the two on the East Asian summer monsoon variability on a highfrequency (HF) component (sub-monthly timescales) and a low-frequency (LF) component (longer than about one month).

The combination of positive EJ type $2\left(\mathrm{EJ}^{+}\right)$, which particularly accounts for the variability of the Okhotsk high among the two types of EJ pattern (EJ type 1 and EJ type 2), and negative $\mathrm{PJ}^{\left(\mathrm{PJ}^{-}\right) \text {patterns }}$ establishes a noticeable tripole structure in the mid-tropospheric geopotential height field of East Asia that is characterized by two positive anomalies over the Okhotsk Sea and the western North Pacific to the north of the Philippines and a negative anomaly over Japan. It is found that the combination of both patterns, $\mathrm{EJ} 2^{+} / \mathrm{PJ}^{-}$, leads to a larger surface temperature decrease in the northeastern part of East Asia than a single teleconnection pattern alone, having a substantial impact on the East Asian summer monsoon circulation. The LF-combination also induces significant cool sea surface temperature anomalies in the vicinity of Japan. In the HF-combined case, the time evolution of a positive height anomaly over the Okhotsk Sea considerably differs from that of the LF-combined one. The HF-anomaly is extremely displaced eastward to the Aleutian Islands a few days after the peak day and occupies part of a newly organized wavetrain pattern across the central North Pacific. Further development of the wavetrain pattern may be attributed to anomalous convective heating related to enhanced synoptic-scale disturbances to the east of Japan.

Both the LF-EJ2 ${ }^{+}$and LF-PJ ${ }^{-}$patterns tend to appear frequently during the post-1980 period, and, as a result, the number of LF-combined cases may have increased in the last two decades. Exceptionally cool summers with significant amounts of rainfall, particularly in Japan, such as the 1993 and 2003 summers, often arise from such an LF-combination.
\end{abstract}

Corresponding author: Ryuichi Kawamura, Universi-

ty of Toyama, 3190 Gofuku, Toyama 930-8555, Japan.

E-mail: kawamura@sci.u-toyama.ac.jp

(C)2008, Meteorological Society of Japan

1 Present affiliation: Japan Weather Association 


\section{Introduction}

The East Asian summer monsoon dominates around the eastern coast of the Asian continent in mid-latitude regions. Its variations are very complicated owing to the occurrence and persistence of summertime teleconnection patterns. Three major waveguides in the vicinity of East Asia enable stationary Rossby waves to propagate eastward. The first waveguide is a polar front jet located over northern Eurasia. Specific teleconnection patterns prevail along this westerly duct, thus indirectly affecting the activity of stationary fronts (Chagma in Korea or Baiu in Japanese) near Korea and Japan through the intensification of the Okhotsk high (e.g., Wang 1992; Wang and Yasunari 1994; Nakamura and Fukamachi 2004). The second is a subtropical jet, the so-called Asian jet, prevailing in the upper troposphere over the Asian continent (e.g., Lu et al. 2002; Wu and Wang 2002; Sato and Takahashi 2006). Enomoto et al. (2003) pointed out that a stationary Rossby wave propagation along the Asian jet contributes to the establishment and reinforcement of the Bonin high. Krishnan and Sugi (2001) showed a significant out-of-phase relationship between the Indian summer monsoon rainfall and Baiu rainfall variations in early summer through the eastward propagation of stationary waves along the Asian jet over the Tibetan Plateau. Finally, the third waveguide is low-level monsoon southwesterly winds along the southeastern periphery of the Asian continent, which is hereafter called the low-level monsoon jet for convenience. The low-level monsoon jet connects with midlatitude westerlies over the North Pacific region, thereby facilitating the dominance of a wavetrain pattern (Kawamura et al. 1996), which is called the Pacific-Japan (PJ) pattern by Nitta (1987). Fairly recently, it was demonstrated that typhoon-induced heating can excite the PJ pattern (Kawamura and Ogasawara 2006; Yamada and Kawamura 2007).

For convenience, the teleconnection patterns propagating along the polar front jet, the upperlevel Asian jet, and the low-level monsoon jet are named the Europe-Japan (EJ), West Asia-Japan (WJ), and PJ patterns, respectively (Wakabayashi and Kawamura 2004). Wakabayashi and Kawamura demonstrated that the $\mathrm{WJ}$ and PJ patterns are the most influential teleconnection modes regarding summertime temperature variability in Japan. Considering their study, Ogasawara and Kawamura (2007) examined the combined effects of the above two teleconnection patterns on anomalous summer weather and found that such a combination causes a larger temperature increase, particularly in northern Japan, than a single teleconnection pattern alone. Their study mainly highlighted extremely hot summer cases in the vicinity of Japan but did not consider exceptionally cool summers and/or increased summer rainfall associated with active quasi-stationary fronts around Korea and Japan.

It is well known, on the other hand, that a distinctive tripole structure tends to appear in the $500-\mathrm{hPa}$ geopotential height anomaly field in East Asia when Japan experiences exceptionally cool summers with significant amounts of summer rainfall, such as the 1993 and 2003 summers (e.g., Kanno 2004; Tachibana et al. 2004; Yasunaka and Hanawa 2006). The tripole pattern is characterized by two positive height anomalies over the Okhotsk Sea and the western North Pacific to the north of the Philippines and a negative anomaly over Japan. Arai and Kimoto (2006) interpreted this pattern as the summertime leading mode prevailing in East Asia. From an alternative viewpoint, it is also possible that the tripole pattern is a simple manifestation of the combination of two different teleconnection patterns. One teleconnection pattern is the EJ type 1 (or EJ type 2) pattern defined by Wakabayashi and Kawamura (2004), which contributes to the intensification of the Okhotsk high, and the other is the PJ pattern, which is induced by anomalous convective heating in the vicinity of the Philippine Sea. A combination of positive EJ1 (or EJ2) and negative PJ patterns might result in the development of the aforementioned tripole pattern. By analogy with Ogasawara and Kawamura (2007), it is assumed that such a combination may cause extraordinary anomalous features in the East Asian summer monsoon circulation.

The present study is sequential to that of Ogasawara and Kawamura (2007), who highlighted the combination of the WJ and PJ patterns. Although both the EJ1 and EJ2 patterns dominate along the polar front jet over northern Eurasia, we focus specifically on the EJ2 pattern in this study because the EJ2 pattern accounts for the behavior of the Okhotsk high better than the EJ1 (Wakabayashi and Kawamura 2004). The main objectives of this study are to: (1) investigate how the positive EJ2 and negative PJ patterns evolve on sub-monthly and interannual timescales, and (2) examine how the combination of the two patterns influences the 
East Asian summer monsoon activity. Section 2 documents the data used and analysis procedures. In Sections 3 and 4, we examine the spatial structures of the positive EJ2 and negative PJ patterns and their combination on sub-monthly and interannual timescales, respectively. Section 5 presents a discussion of a recent tendency of their combination in relation to the frequent occurrence of extreme summers. A concluding summary of the results is given in Section 6 .

\section{Data used and analysis procedures}

The datasets used in this study consist of: (1) the European Center for Medium-Range Weather Forecasts (ECMWF) reanalysis (ERA-40) data with a spatial resolution of $2.5^{\circ}$ longitude by $2.5^{\circ}$ latitude for the period of 1958-2001, (2) daily sea surface temperature (SST) data for the period of 1979-2001, provided by the Centennial in situ Observation-Based Estimates of variability of SST and marine-meteorological variables (COBE-SST) project (Ishii et al. 2005), and (3) daily mean surface air temperature data derived from the fifteen observational stations of the Japan Meteorological Agency (JMA). The JMA observational stations used for this study, which coincide with those considered in Ogasawara and Kawamura (2007), are divided into three regions: northern Japan (Abashiri, Nemuro, Suttsu, Yamagata, and Ishinomaki), eastern Japan (Fushiki, Nagano, Mito, Iiida, and Choushi), and western Japan (Sakai, Hamada, Hikone, Tadotsu, and Miyazaki).

According to Wakabayashi and Kawamura (2004), EJ1, EJ2, and PJ teleconnection indices are concisely defined as follows:

$$
\begin{aligned}
E J 1= & {\left[Z^{*}{ }_{500}\left(45^{\circ} \mathrm{E}, 60^{\circ} \mathrm{N}\right)-Z^{*}{ }_{500}\left(100^{\circ} \mathrm{E}, 65^{\circ} \mathrm{N}\right)\right.} \\
& \left.+Z^{*}{ }_{500}\left(145^{\circ} \mathrm{E}, 60^{\circ} \mathrm{N}\right)\right] / 3 \\
E J 2= & {\left[Z^{*}{ }_{500}\left(70^{\circ} \mathrm{E}, 60^{\circ} \mathrm{N}\right)\right.} \\
& \left.+Z^{*}{ }_{500}\left(150^{\circ} \mathrm{E}, 57.5^{\circ} \mathrm{N}\right)\right] / 2 \\
P J= & {\left[Z^{*}{ }^{*}{ }_{50}\left(155^{\circ} \mathrm{E}, 35^{\circ} \mathrm{N}\right)\right.} \\
& \left.-Z^{*}{ }_{850}\left(125^{\circ} \mathrm{E}, 22.5^{\circ} \mathrm{N}\right)\right] / 2
\end{aligned}
$$

where $Z^{*}{ }_{500}$ and $Z^{*}{ }_{850}$ indicate the geopotential height anomalies at the 500- and $850-\mathrm{hPa}$ levels, respectively. The 500- and $850-\mathrm{hPa}$ levels are selected considering the polar front jet and the lowlevel monsoon jet, respectively. In order to compute those teleconnection indices for the period of 1958-2001, we used the daily mean geopotential height during the three-month period from June to August, obtained from the ERA-40. By applying a combination of two simple low-pass filters (the 3-day-weighted running average and 31-day running average) to the daily data, we first partitioned total variations into a high-frequency (HF) component (sub-monthly timescales) and a low-frequency (LF) component (longer than about one month). The 3-day filter is a 1-2-1 filter. The HF component is obtained as the difference of 3-day filtered minus 31-day filtered data. The LF component is 31-day filtered data, but the annual cycle is removed in the LF component, using the climatology of 1958 -2001. The LF component is largely dependent on the interannual variability, although it contains part of the intraseasonal variability. These filtering procedures are quite similar to those conducted by Ogasawara and Kawamura (2007). Second, we computed the standard deviation $(\sigma)$ of the filtered indices and then defined a period exceeding $+1.5 \sigma$ and $+1.0 \sigma$ as a specific event in which the positive $\mathrm{EJ} 2\left(\mathrm{EJ} 2^{+}\right)$pattern predominates on the $\mathrm{HF}$ and $\mathrm{LF}$ components, respectively. The same definition is also applied for the positive EJ1 (EJ1 $\left.1^{+}\right)$pattern. As for the negative $\mathrm{PJ}\left(\mathrm{PJ}^{-}\right)$pattern, threshold values of $-1.5 \sigma$ and $-1.0 \sigma$ are applied for the HF and LF components, respectively. For both components, we constructed composite maps for the geopotential height, wind vector, temperature, and other variables. Here, day 0 denotes the peak day of the $\mathrm{EJ} 2^{+}, \mathrm{EJ}^{+}$, and $\mathrm{PJ}^{-}$events.

\section{Low-frequency (LF) component}

Following the criterions for the LF component, we extracted 23 and 30 events as the active phases of the $\mathrm{EJ}^{+}$and $\mathrm{PJ}^{-}$patterns, respectively. To examine the combination of the $\mathrm{EJ}^{+}$and $\mathrm{PJ}^{-}$patterns, we selected cases in which day 0 of a $\mathrm{PJ}^{-}$event is present within the range from day -20 to day +20 of an $\mathrm{EJ} 2^{+}$event in order to increase the number of cases and, as a consequence, extracted 10 events as the combination of the two patterns. The averages of the normalized LF-EJ2 and LF-PJ indices on day 0 for the 10 events are +1.32 and -1.35 , respectively. The correlation between the two indices is -0.16 .

\subsection{Spatial structures of LF-teleconnection patterns}

Figure 1 reveals the composites of filtered 500$\mathrm{hPa}$ geopotential height anomalies on day -10 , day 0 , and day +10 for the $\mathrm{EJ} 2^{+}$pattern along with the wave activity fluxes at the same level. Here the climatology of the 31-day filtered data is used as the basic field in computing the wave activity fluxes 
defined by Takaya and Nakamura (2001). The EJ2 ${ }^{+}$ pattern, which exhibits a dipole structure, is characterized by two salient positive height anomalies over the Ural Mountains and the Okhotsk Sea. On day -10 , the positive height anomaly over the Ural Mountains is already evident, but the other positive anomaly over the Okhotsk Sea is relatively weak. Eastward wave activity fluxes prevail across northern Eurasia, thus contributing to the reinforcement of the positive anomaly over the Okhotsk Sea from day -10 to day 0 . The two centers of action reach their peak on day 0 . Although both of the positive anomalies are gradually weakened, dipolelike features persist until around day +10 . In a similar fashion, we present, in Fig. 2, composites of filtered $850-\mathrm{hPa}$ geopotential height anomalies for the $\mathrm{PJ}^{-}$pattern along with wave activity fluxes. The $\mathrm{PJ}^{-}$pattern, which consists of a positive height anomaly north of the Philippines and a negative anomaly east of Japan, dominates from day -10 to day +10 and is accompanied by northward wave activity fluxes. Since the PJ pattern is well linked with

\section{0 \& WAF500 \\ $[\mathrm{LF}-\mathrm{EJ} 2(+)]\langle 23\rangle$ \\ (a) $\operatorname{day}(-10)$}

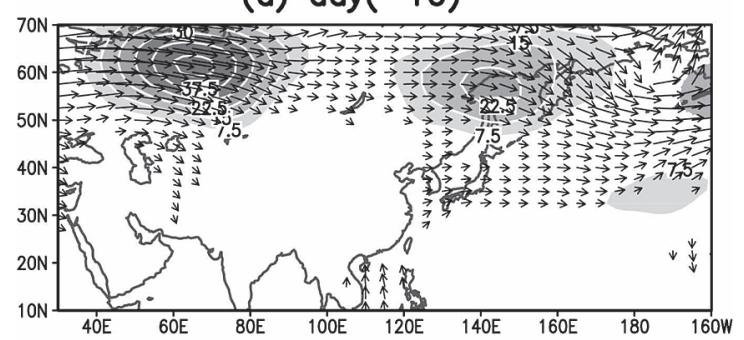

(b) $\operatorname{day}(0)$
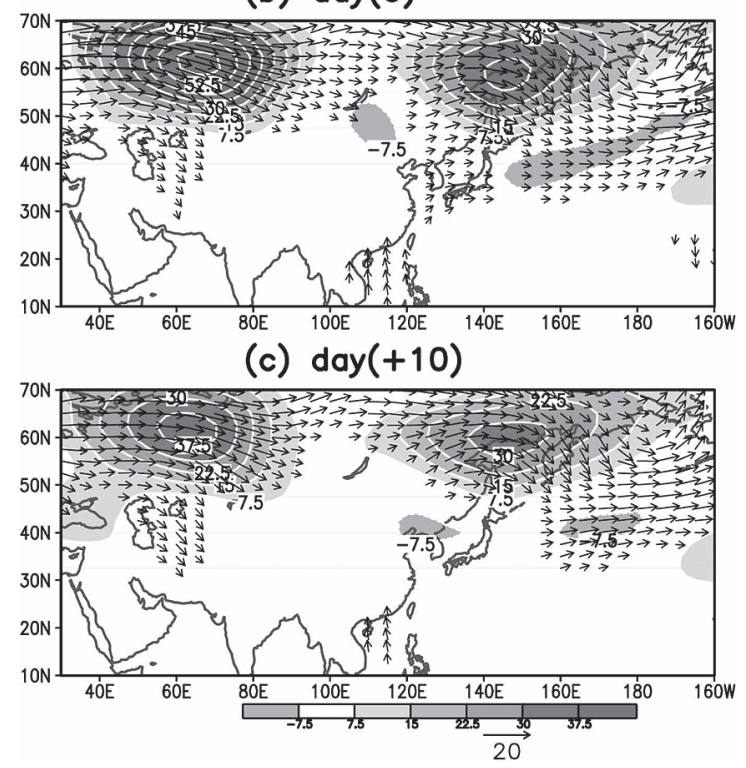

Fig. 1. Composite maps (23 events) of filtered $500-\mathrm{hPa}$ geopotential height anomalies and wave activity fluxes on day -10 , day 0 , and day +10 for the LF$\mathrm{EJ}^{+}$teleconnection pattern. Day 0 denotes the peak phase of the LF-EJ2 ${ }^{+}$. The contour interval for height is $7.5 \mathrm{~m}$. The reference arrow is $20 \mathrm{~m}^{2} \mathrm{~s}^{-2}$. Fluxes of less than $3 \mathrm{~m}^{2} \mathrm{~s}^{-2}$ are suppressed.
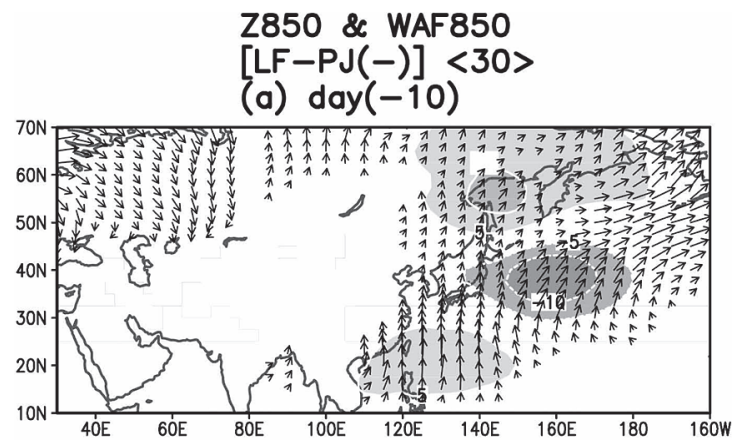

(b) $\operatorname{day}(0)$
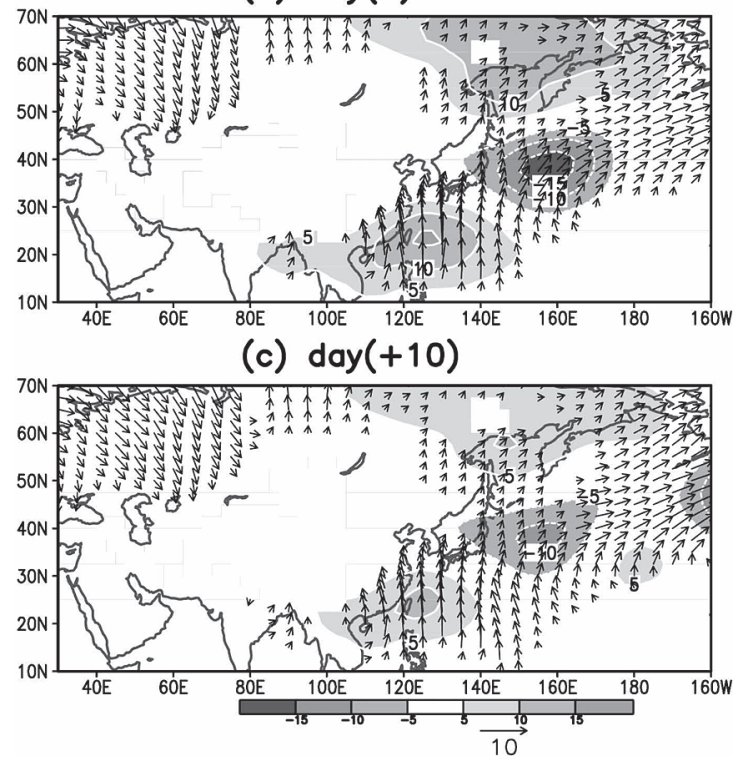

Fig. 2. Composite maps (30 events) of filtered 850-hPa geopotential height anomalies and wave activity fluxes on day -10 , day 0 , and day +10 for the LF-PJ ${ }^{-}$pattern. Day 0 denotes the peak phase of the LF$\mathrm{PJ}^{-}$. The contour interval for height is $5 \mathrm{~m}$. The reference arrow is $10 \mathrm{~m}^{2} \mathrm{~s}^{-2}$. Fluxes of less than $1 \mathrm{~m}^{2} \mathrm{~s}^{-2}$ are suppressed. 
the activity of the Western North Pacific monsoon, the negative phase of PJ implies a weakening of its monsoon. An intriguing feature is that a weak positive anomaly appears over eastern Siberia and the Okhotsk Sea. The coexistence of this anomaly and the $\mathrm{PJ}^{-}$pattern shows a weak tripole-like pattern. It seems that part of wave activity fluxes in lowlatitude regions is not necessarily in consistency with the $850-\mathrm{hPa}$ height anomaly pattern. This might reflect a limitation of the application of wave activity flux based on a quasi-geostrophic approximation because tropical atmosphere is dominated by ageostrophic circulation.

Figure 3 demonstrates composite maps (10 events) of filtered $850-\mathrm{hPa}$ geopotential height anomalies for the combination of the $\mathrm{EJ}^{+}$and $\mathrm{PJ}^{-}$ patterns. As expected, a noticeable tripole pattern is well organized on day 0 . This tripole pattern exhibits both an intensification of the Okhotsk high and a weakening of the Bonin high (or less westward extension of the North Pacific high toward Japan). A positive anomaly in the vicinity of the Ural Mountains rapidly decays after day 0 , but, in contrast, a positive anomaly over the Okhotsk Sea tends to be persistent until day +10 . This feature is also very similar to that at the 500-hPa level (not shown). Such persistence might arise from a possible interaction between the $\mathrm{EJ}^{+}$and $\mathrm{PJ}^{-}$patterns. In the same way, we also examined the behavior of the $\mathrm{EJ}^{+}$pattern and its combination with the $\mathrm{PJ}^{-}$ pattern and found a less organized tripole pattern than the $\mathrm{EJ} 2^{+} / \mathrm{PJ}^{-}$pattern.

\subsection{Impacts of LF-teleconnection patterns}

In this subsection, we present the single and combined effects of the $\mathrm{EJ}^{+}$and $\mathrm{PJ}^{-}$patterns on the summertime temperature field in East Asia, particularly in Korea and Japan, and the associated SST field over the western North Pacific Ocean. Figure 4 shows composites of the filtered $850-\mathrm{hPa}$ geopotential height, 850-hPa wind vector, and SST anomalies on day 0 for the $\mathrm{EJ}^{+}$and $\mathrm{PJ}^{-}$patterns and their combined cases. As for these composites, we consider 15, 18, and 6 events for the $\mathrm{EJ}^{+}, \mathrm{PJ}^{-}$, and $\mathrm{EJ} 2^{+} / \mathrm{PJ}^{-}$combined cases, respectively, because of the shortage of SST data available. In the $\mathrm{EJ}^{+}$single case (upper panel), an anomalous anticyclone is indicated over the Okhotsk Sea, accompanied by a positive SST anomaly, while, in the $\mathrm{PJ}^{-}$ single case (middle panel), a cyclonic circulation anomaly is significant to the east of Japan, concurrent with a negative SST anomaly over the sur- rounding regions. In the $\mathrm{EJ} 2^{+} / \mathrm{PJ}^{-}$combined case (lower panel), the negative SST anomaly is more prominent in the vicinity of Japan. In the meantime, the summer monsoon rainfall is anticipated to increase through enhanced quasi-stationary fronts, such as the Baiu front (e.g., Yasunaka and Hanawa 2006). Corresponding to the atmospheric tripole pattern, another tripole-like structure also becomes obvious in the SST anomaly filed. Likewise, relatively weak positive SST anomalies extend from the Philippine Sea through the tropical Indian Ocean,
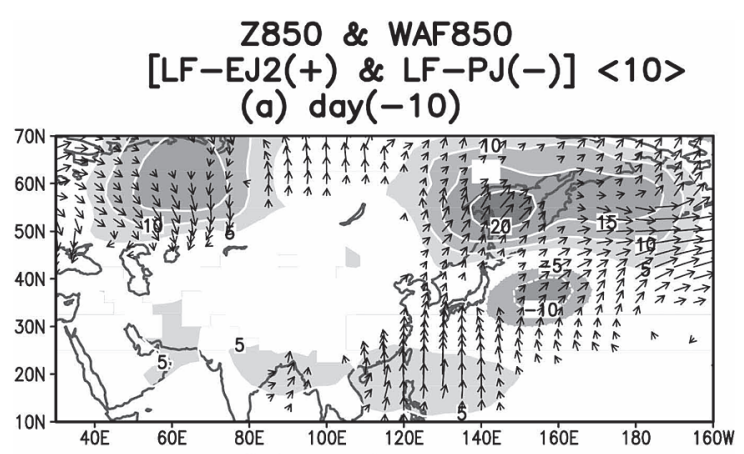

(b) $\operatorname{day}(0)$
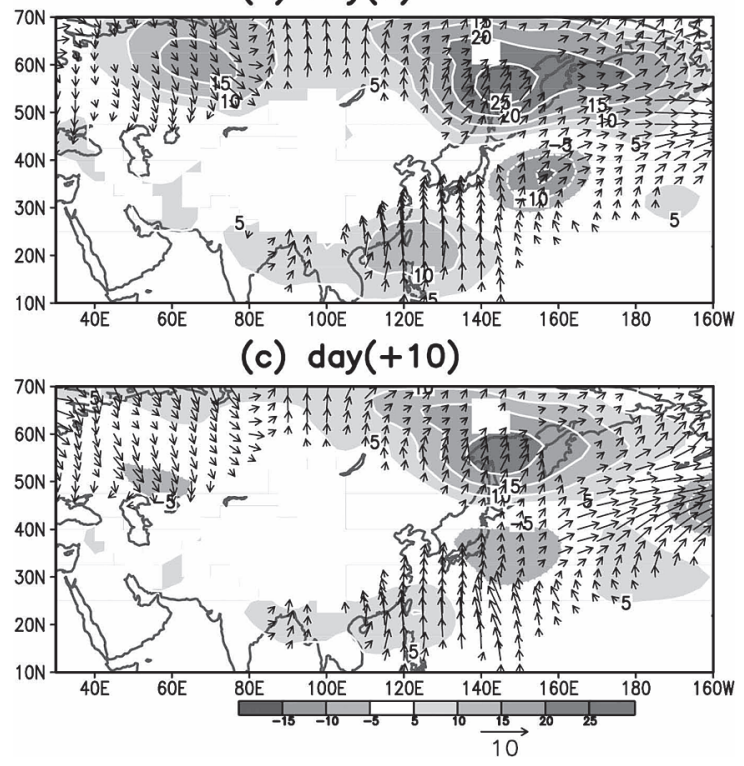

Fig. 3. Composite maps of filtered $850-\mathrm{hPa}$ geopotential height anomalies and wave activity fluxes on day -10 , day 0 , and day +10 for the combination of the LF-EJ $2^{+}$ and LF-PJ ${ }^{-}$patterns based on 10 events. Day 0 denotes the peak phase of the LF$\mathrm{PJ}^{-}$. The contour interval for height is $5 \mathrm{~m}$. The reference arrow is $10 \mathrm{~m}^{2} \mathrm{~s}^{-2}$. Fluxes of less than $1 \mathrm{~m}^{2} \mathrm{~s}^{-2}$ are suppressed. 


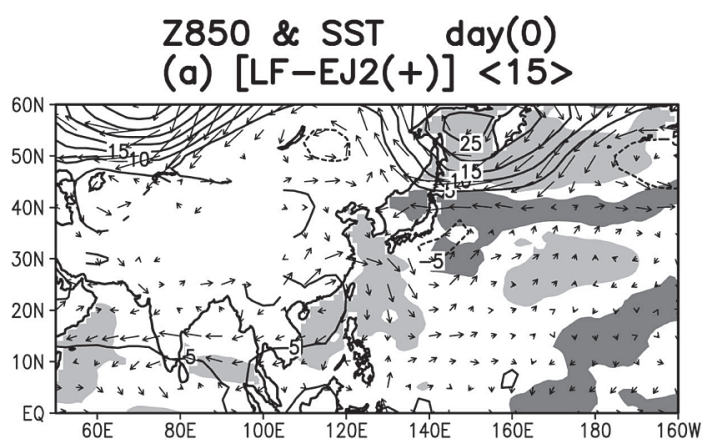

(b) $[\mathrm{LF}-\mathrm{PJ}(-)]\langle 18\rangle$

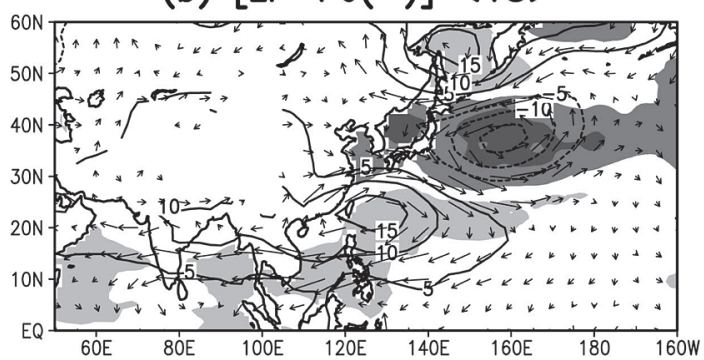

(c) $[\mathrm{LF}-\mathrm{EJ} 2(+)$ \& LF-PJ(-)] $\langle 6\rangle$

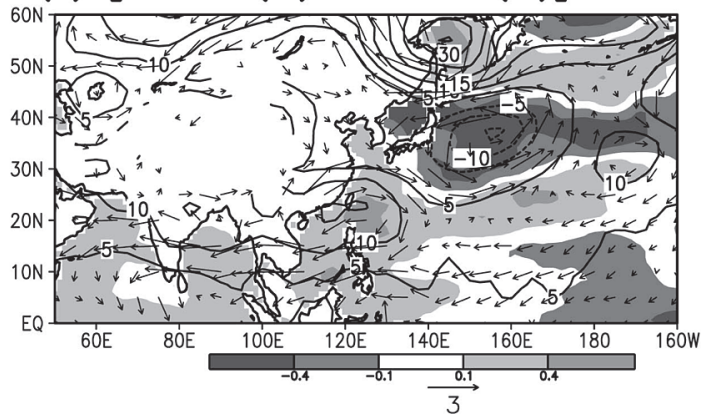

Fig. 4. Composites of filtered $850-\mathrm{hPa}$ geopotential height, $850-\mathrm{hPa}$ wind vector, and SST anomalies on day 0 for the (a) LF-EJ2 ${ }^{+}$single event, (b) LF-PJ $^{-}$single event, and (c) their combined events. The contour interval for height is $5 \mathrm{~m}$. The reference arrow is $3 \mathrm{~m} \mathrm{~s}^{-1}$.

together with anomalous easterly winds, implying a weakening of the South Asian summer monsoon activity.

The left panel of Fig. 5 shows a composite map of the filtered $1000-\mathrm{hPa}$ temperature anomalies on day 0 for the $\mathrm{EJ} 2^{+} / \mathrm{PJ}^{-}$combined event along with the $1000-\mathrm{hPa}$ wind vector anomaly. Two noticeable low-temperature anomalies cover northern Japan and coastal areas near Korea. These temperature anomalies are accompanied by anomalous northeasterly winds, suggesting the predominance of cold advection induced by the tripole pattern because the north-south gradient of the temperature is large in those regions (not shown). The right panel of this figure shows composites of the surface air temperature anomalies from day -20 to day +20 using five JMA meteorological observation stations in the northern part of Japan, as mentioned in the previous section. The composite temperature anomalies for $\mathrm{EJ}_{2} / \mathrm{PJ}^{-}$combination, $\mathrm{EJ} 2^{+}$alone, and $\mathrm{PJ}^{-}$alone are denoted by a thick line, a thin line, and a dashed line, respectively. To compare these three relative impacts on the summertime temperatures in northern Japan, it is noteworthy here that, for instance, the average of the EJ2 index in the $\mathrm{EJ} 2^{+} / \mathrm{PJ}^{-}$combined case is different from that in the $\mathrm{EJ}^{+}$single case. Thus, the composite temperature anomaly values of the $\mathrm{EJ}^{+}$and $\mathrm{PJ}^{-}$single cases are changed to scale on the basis of the $\mathrm{EJ} 2^{+} / \mathrm{PJ}^{-}$combined case, considering the average of a normalized teleconnection index at each event extracted. As for the single cases, the $\mathrm{PJ}^{-}$pattern leads to a larger temperature decrease in northern Japan than the $\mathrm{EJ} 2^{+}$pattern alone. If the $\mathrm{PJ}^{-}$pattern is combined with the $\mathrm{EJ} 2^{+}$pattern, the temperature decreases further, and low-temperature conditions (below $-1^{\circ} \mathrm{C}$ ) tend to persist until day +20 , thus increasing the possibility of serious damage to crops due to cold weather in northern Japan. Thus, the appearance of the $\mathrm{EJ} 2^{+} / \mathrm{PJ}^{-}$combination strongly influences the East Asian summer monsoon circulation and is associated with anomalous summer weather, especially in Korea and Japan.

As indicated in Fig. 4, the LF-combination induces the negative SST anomaly in the vicinity of Japan, which may in turn contribute, to some extent, to the persistence of the low-temperature conditions in northern Japan after the peak day. We also need to investigate a possible two-way interaction between the atmosphere and the ocean to further understand the occurrence and persistence of the anomalous summer weather in East Asia.

\section{High-frequency (HF) component}

According to the criterions for the HF component, we obtained 99 and 105 events as active phases of the $\mathrm{EJ} 2^{+}$and $\mathrm{PJ}^{-}$patterns, respectively. We also extracted combined cases of the two patterns, in which day 0 of a $\mathrm{PJ}^{-}$event is present within the range from day -5 to day +5 of an $\mathrm{EJ} 2^{+}$event; as a result, we derived 15 events as the mixture of the two patterns. The averages of the normalized HF$\mathrm{EJ}^{+}{ }^{+}$and HF-PJ ${ }^{-}$indices on day 0 for the 15 events 


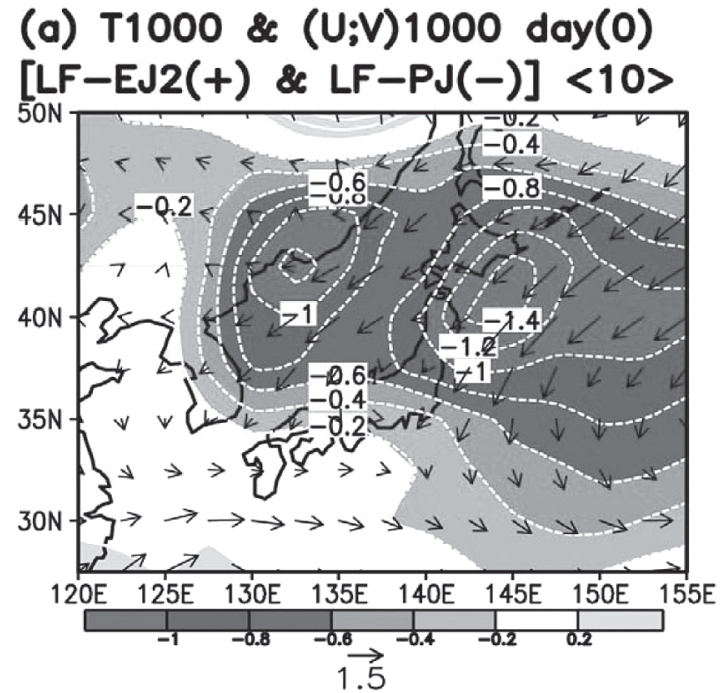

\section{(b) SAT(Northern Japan) Time Series [LF]}

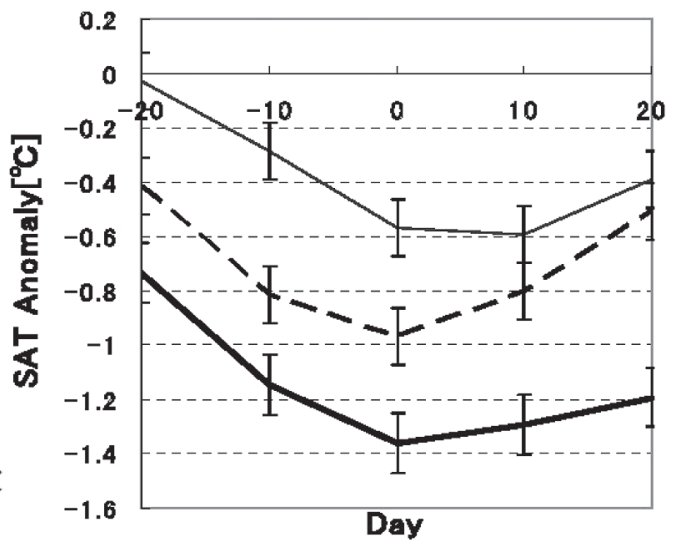

Fig. 5. Anomalous features in the northeastern part of East Asia for the LF-EJ2 ${ }^{+} / \mathrm{LF}^{-P J}{ }^{-}$combined event. (a) Composite maps of filtered 1000-hPa temperature (contour) and wind vector anomalies on day 0 . The contour interval for temperature is $0.2^{\circ} \mathrm{C}$. The reference arrow is $1.5 \mathrm{~m} \mathrm{~s}^{-1}$. (b) Composite surface air temperature anomalies in northern Japan from day -20 to day +20 . The LF-EJ2 $2^{+} / \mathrm{LF}^{-} \mathrm{PJ}^{-}$ combined event, LF-EJ2 ${ }^{+}$single event, and $\mathrm{LF}-\mathrm{PJ}^{-}$single event are denoted by thick solid, thin solid, and dashed lines, respectively, along with their error bars.

are +1.77 and -2.07 , respectively. Here, it is noteworthy that HF-EJ2 is quite independent of HF-PJ because the correlation between the two indices is -0.05 .

\subsection{Spatial structures of HF-teleconnection patterns}

Figure 6 exhibits composite maps of filtered 500$\mathrm{hPa}$ geopotential height anomalies on day -2 , day 0 , and day +2 for the HF-EJ $2^{+}$pattern along with wave activity fluxes. Here the 31-day filtered data is used as the basic field in computing the wave activity fluxes on the HF component. Although the HF-EJ $2^{+}$pattern is basically similar to the LF-EJ $2^{+}$ pattern, which exhibits a twin-blocking structure, there is a significant difference; namely, in the HF pattern, the positive height anomalies over both the Ural Mountains and the Okhotsk high migrate eastward from day -2 to day +2 . The positive anomaly over the Okhotsk Sea on day 0 implies the intensification of the Okhotsk high, but its magnitude gradually weakens from day 0 to day +2 . The time evolution of the HF-PJ ${ }^{-}$pattern at the $850-\mathrm{hPa}$ level is also indicated in Fig. 7. Focusing on day 0, a distinctive wavetrain pattern is established from the north of the Philippines through the central North Pacific, accompanied by northeastward and eastward fluxes. The most notable difference be- tween the HF- and LF-PJ ${ }^{-}$patterns is the absence of significant anomalies over eastern Siberia and the Okhotsk Sea in the HF pattern. Furthermore, the negative anomaly east of Japan on day 0 is more evident than the surrounding anomalies. Figure 8 shows the composites of filtered $850-\mathrm{hPa}$ geopotential height anomalies for the combination of the HF-EJ $2^{+}$and HF-PJ ${ }^{-}$patterns. In contrast to Fig. 6, this figure shows that a positive anomaly in the vicinity of the Okhotsk Sea is extremely displaced eastward to the Aleutian Islands from day 0 to day +2 . After that, the positive anomaly persists there until day +5 (see also Fig. 13) and occupies part of a newly organized wavetrain pattern across the central Pacific. These features are not simple manifestations of eastward-traveling synoptic-scale disturbances but reflect establishment of stationary wave propagation. A negative anomaly around Japan is almost stationary from day -2 to day +2 . It is conceivable that enhanced northeastward wave activity fluxes emanating from the negative anomaly east of Japan play a vital role in inducing the wavetrain pattern. On the other hand, another positive anomaly around the Ural Mountains tends to decay from day 0 to day +2 , but the anomalous positive area is found to extend westward into Europe on day +2 , a topic which will be discussed 


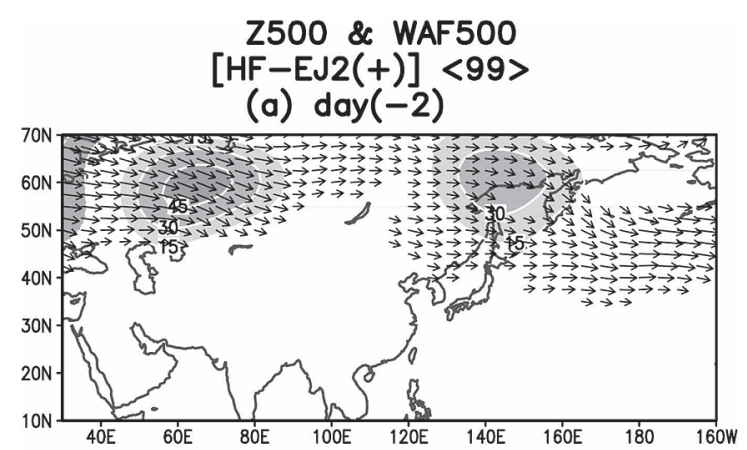

(b) $\operatorname{day}(0)$

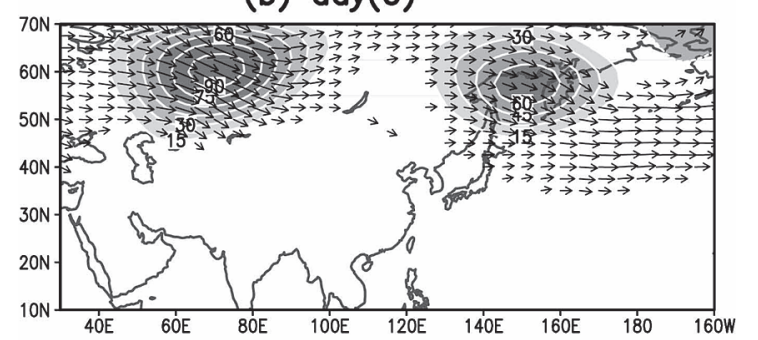

(c) $\operatorname{day}(+2)$

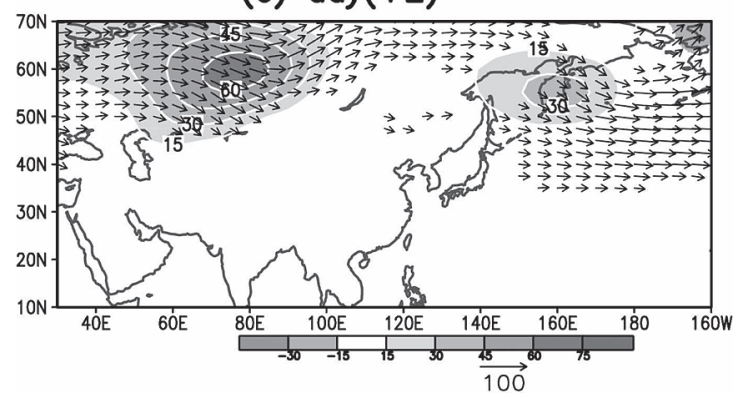

Fig. 6. Composite maps (99 events) of filtered 500-hPa geopotential height anomalies and wave activity fluxes on day -2 , day 0 , and day +2 for the HF-EJ2 ${ }^{+}$teleconnection pattern. Day 0 denotes the peak phase of the HF-EJ2 ${ }^{+}$. The contour interval for height is $15 \mathrm{~m}$. The reference arrow is $100 \mathrm{~m}^{2} \mathrm{~s}^{-2}$. Fluxes of less than $20 \mathrm{~m}^{2} \mathrm{~s}^{-2}$ are suppressed.

briefly in the next section.

To understand how the above teleconnection patterns are linked with rainfall anomalies over East Asia and the western North Pacific, we present, in Fig. 9, composites of filtered rainfall and $850-\mathrm{hPa}$ geopotential height anomalies on day 0 for the HF$\mathrm{EJ}^{+}$and HF-PJ ${ }^{-}$patterns and their combined cases. In the $\mathrm{EJ}^{+}$single case, no remarkable rainfall anomalies are found in those regions, but, in the $\mathrm{PJ}^{-}$single case, a significant positive rainfall anomaly is found in conjunction with the negative anom-

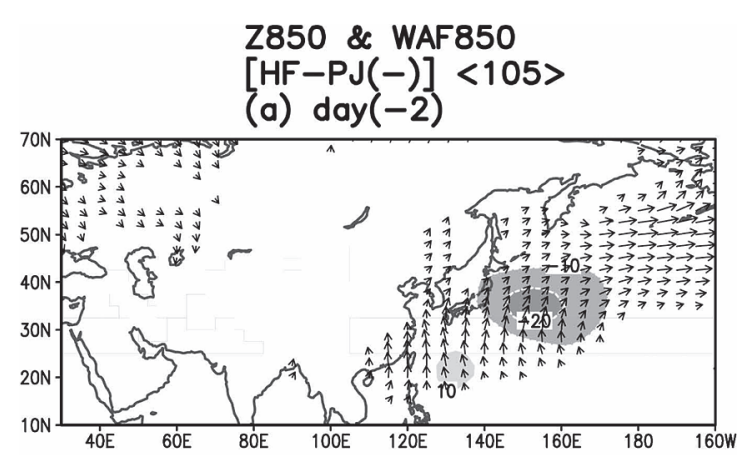

(b) $\operatorname{day}(0)$

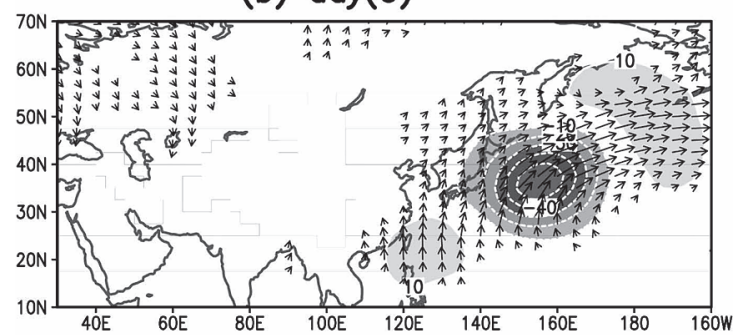

(c) $\operatorname{day}(+2)$

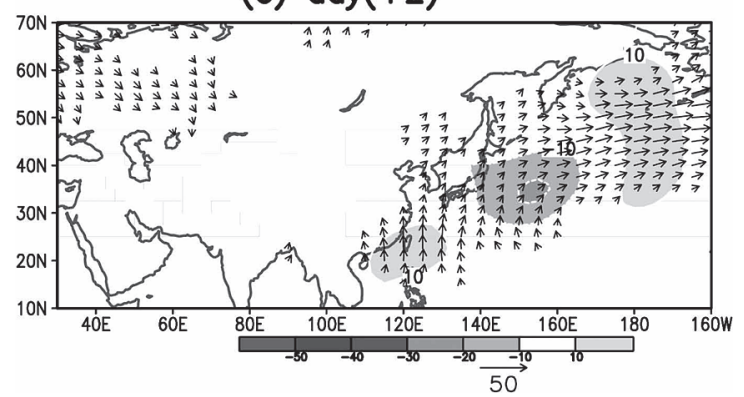

Fig. 7. Composite maps (105 events) of filtered $850-\mathrm{hPa}$ geopotential height anomalies and wave activity fluxes on day -2 , day 0 , and day +2 for the $\mathrm{HF}^{-\mathrm{PJ}^{-}}$ pattern. Day 0 denotes the peak phase of the HF-PJ'. The contour interval for height is $10 \mathrm{~m}$. The reference arrow is $50 \mathrm{~m}^{2} \mathrm{~s}^{-2}$. Fluxes of less than $5 \mathrm{~m}^{2} \mathrm{~s}^{-2}$ are suppressed.

alous height east of Japan, and a negative rainfall anomaly is located north of the Philippines. Such a feature is also seen in the $\mathrm{EJ} 2^{+} / \mathrm{PJ}^{-}$combined case. Surface weather maps show that the increased rainfall to the east of Japan corresponds well to quasi-stationary fronts in many cases (not shown), suggesting the enhanced activity of synoptic-scale disturbances. Considering the results of both Figs. 8 and 9, anomalous convective heating related to the enhanced synoptic-scale disturbances to the east of Japan appears to contribute to further de- 


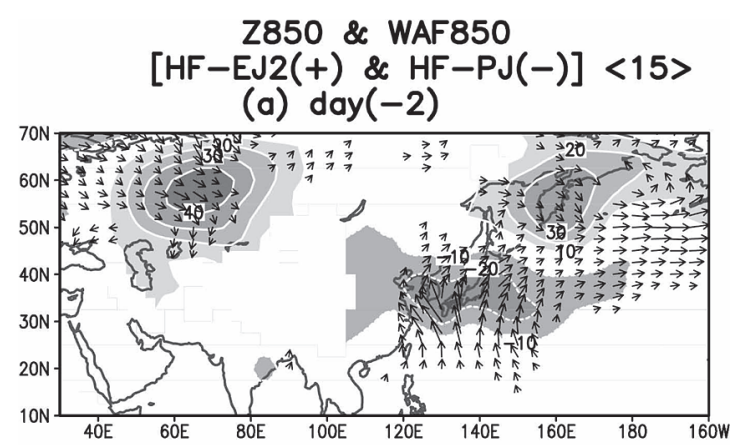

(b) $\operatorname{day}(0)$

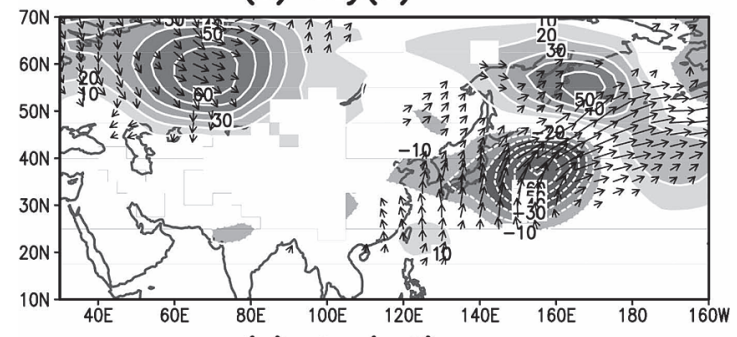

(c) $\operatorname{day}(+2)$

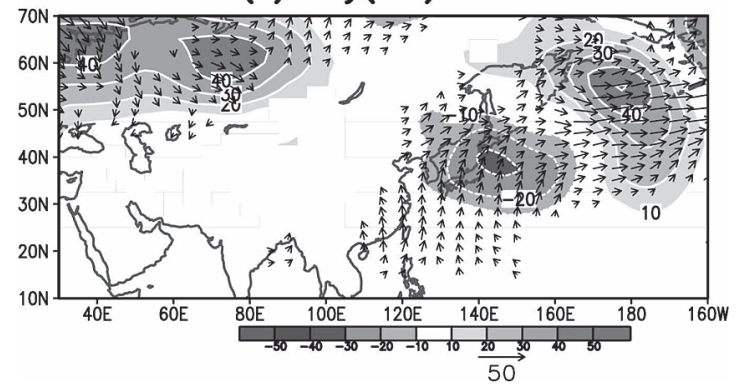

Fig. 8. Composite maps of filtered $850-\mathrm{hPa}$ geopotential height anomalies and wave activity fluxes on day -2 , day 0 , and day +2 for the combination of the HF-EJ2 ${ }^{+}$ and $\mathrm{HF}-\mathrm{PJ}^{-}$patterns based on 15 events. Day 0 denotes the peak phase of the HF$\mathrm{PJ}^{-}$. The contour interval for height is $10 \mathrm{~m}$. The reference arrow is $50 \mathrm{~m}^{2} \mathrm{~s}^{-2}$. Fluxes of less than $5 \mathrm{~m}^{2} \mathrm{~s}^{-2}$ are suppressed.

velopment of the wavetrain pattern over the central North Pacific through a stationary Rossby wave propagation.

\subsection{Impacts of HF-teleconnection patterns}

The left panel of Fig. 10 demonstrates a composite map of filtered $1000-\mathrm{hPa}$ temperature anomalies on day 0 for the $\mathrm{EJ} 2^{+} / \mathrm{PJ}^{-}$combined event along with the $1000-\mathrm{hPa}$ wind vector anomaly. The overall features of the temperature and circulation anomalies are similar to those for the LF component.

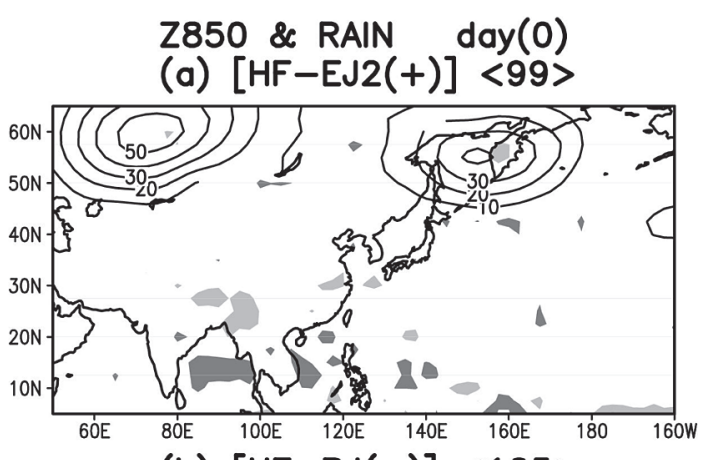

(b) $[\mathrm{HF}-\mathrm{PJ}(-)]\langle 105\rangle$

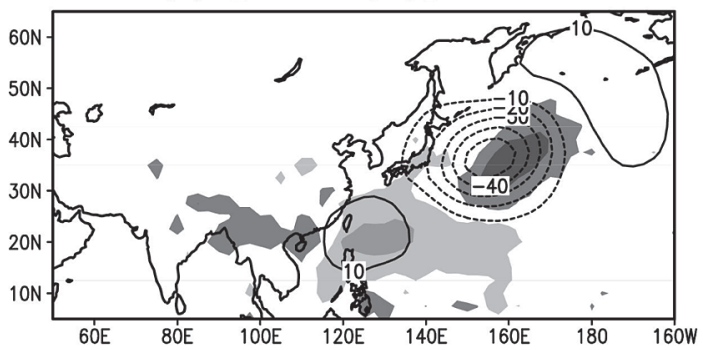

(c) $[\mathrm{HF}-\mathrm{EJ} 2(+)$ \& $\mathrm{HF}-\mathrm{PJ}(-)]\langle 15\rangle$

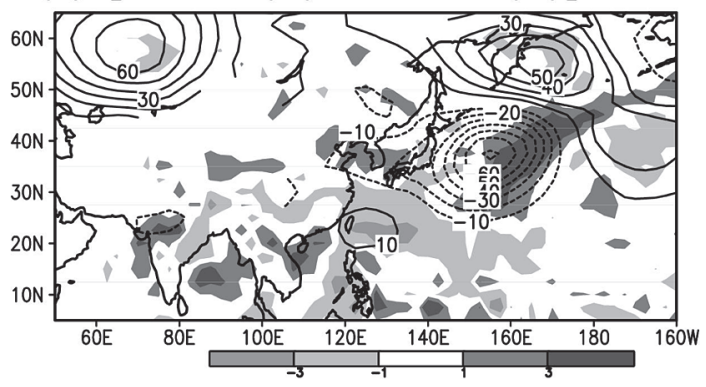

Fig. 9. Composites of filtered 850-hPa geopotential height and rainfall anomalies on day 0 for the (a) HF-EJ2 $2^{+}$single event, (b) HF-PJ $^{-}$single event, and (c) their combined events. The contour interval for height is $10 \mathrm{~m}$. The shading interval for rainfall is $2 \mathrm{~mm} \mathrm{day}^{-1}$.

Low-temperature anomalies (below $-1^{\circ} \mathrm{C}$ ), together with anomalous northerlies, cover the northern part of Japan. The right panel of this figure is the same as that in Fig. 5b but for the HF component. For the HF component as well, the impact of the $\mathrm{PJ}^{-}$pattern alone on the anomalous temperatures in northern Japan is much larger than that of $\mathrm{EJ} 2^{+}$ pattern alone. In the $\mathrm{EJ} 2^{+} / \mathrm{PJ}^{-}$combined case, the change in the surface air temperature is in excess of $2^{\circ} \mathrm{C}$ during the four-day period from day -3 to day +1 . The low-temperature conditions tend to last for five or six days. Although we examined summertime temperature variations in eastern and 


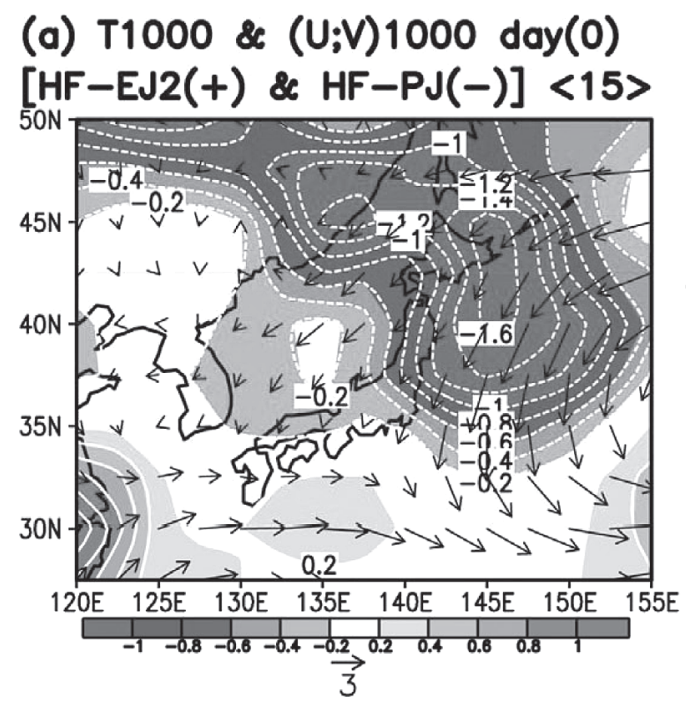

\section{(b) SAT(Northern Japan) Time Series [HF]}

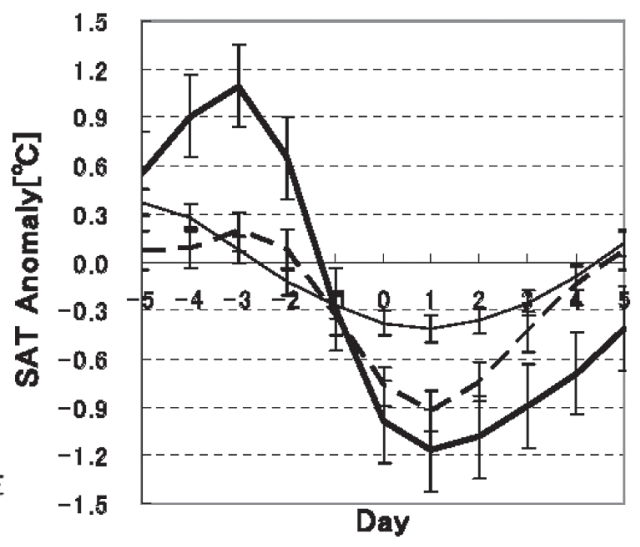

Fig. 10. Anomalous features in the northeastern part of East Asia for the HF-EJ2 $/ \mathrm{HF}^{-\mathrm{PJ}^{-}}$combined event. (a) Composite map of filtered 1000-hPa temperature (contour) and wind vector anomalies on day 0 . The contour interval for temperature is $0.2^{\circ} \mathrm{C}$. The reference arrow is $3 \mathrm{~m} \mathrm{~s}^{-1}$. (b) Composite surface air temperature anomalies in northern Japan from day -5 to day +5 . The HF-EJ2 $2^{+} / \mathrm{HF}^{-\mathrm{PJ}^{-}}$combined event, HF-EJ $2^{+}$single event, and HF-PJ ${ }^{-}$single event are denoted by thick solid, thin solid, and dashed lines, respectively, along with their error bars.

western Japan, furthermore, the combined effect of the HF-EJ2 ${ }^{+}$and $\mathrm{HF}^{-\mathrm{PJ}^{-}}$patterns on the temperature variations in those regions is less clear than that in northern Japan, as can be inferred from Fig. 10a. It is noteworthy, likewise, that the impact of the $\mathrm{EJ} 1^{+} / \mathrm{PJ}^{-}$combination is smaller than that of the $\mathrm{EJ} 2^{+} / \mathrm{PJ}^{-}$combination.

\section{Discussion}

In the previous sections, we demonstrated how the combination of the $\mathrm{EJ}^{+}$and $\mathrm{PJ}^{-}$patterns results in the development of a tripole-like structure on the LF and HF components and has a significant impact on the change in the East Asian summer monsoon circulation. Since the correlation coefficient between the LF-EJ2 and LF-PJ teleconnection indices is -0.16 , as stated earlier, it is very likely that the independence between the two is not consistent with the results obtained by Arai and Kimoto (2006), who extracted the tripole pattern as the summertime leading mode in the $500-\mathrm{hPa}$ geopotential height anomaly field in East Asia. We would like to briefly discuss this discrepancy first and then show an additional finding on a possible linkage through a teleconnection between East Asia and Europe.

\subsection{Frequent appearance of the tripole pattern in recent years}

Following Arai and Kimoto (2006), we similarly performed an empirical orthogonal function (EOF) analysis to the monthly mean $500-\mathrm{hPa}$ geopotential height anomaly field $\left(80^{\circ}-160^{\circ} \mathrm{E}, 20^{\circ}-70^{\circ} \mathrm{N}\right)$ in East Asia during summer and extracted each summertime leading mode with respect to two specific periods (1958-1979 and 1980-2001). Figure 11 shows the regression patterns of $500-\mathrm{hPa}$ geopotential height anomalies with the time coefficients of each leading mode. The leading mode of the pre-1980 period is characterized by a positive anomaly north of the Okhotsk Sea and a negative anomaly east of Japan, which is similar to the LF$\mathrm{EJ} 2^{+}$pattern, whereas that of the post-1980 period accounts for a clear tripole pattern, although a negative anomaly over Japan is somewhat obscure. This suggests that such a tripole-like structure does not always predominate during the entire period but tends to prevail in the last two decades.

To further confirm that from another perspective, we computed the total number of days exceeding the threshold values of $+1.0 \sigma$ for the LF-EJ2 ${ }^{+}$

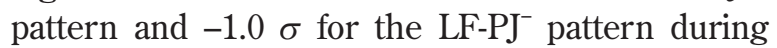
summer and showed its interannual variations in Fig. 12. The number of days when the LF-EJ2 $2^{+}$pat- 


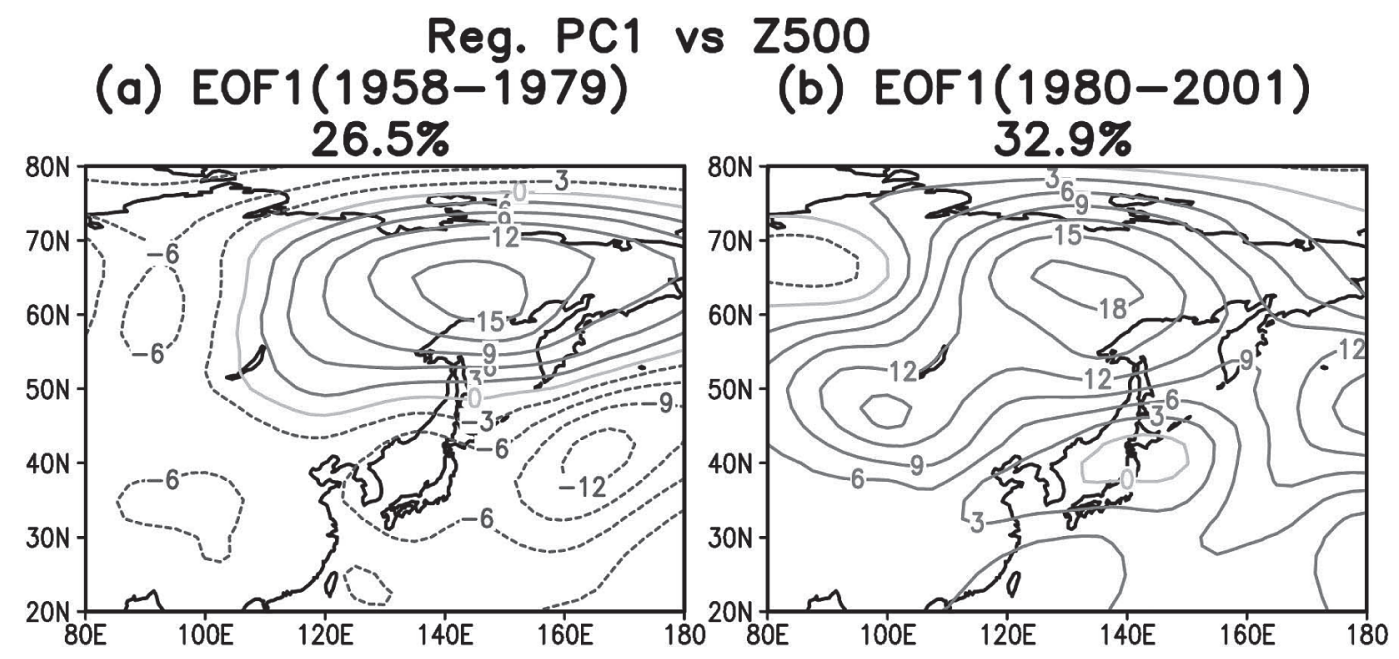

Fig. 11. Regression patterns of 500-hPa geopotential height anomalies with the time coefficients of each leading mode, which is derived by applying the EOF analysis to the $500-\mathrm{hPa}$ geopotential height anomalies for (a) the 1958-1979 and (b) the 1980-2001 periods. The contour interval for height is $3 \mathrm{~m}$.

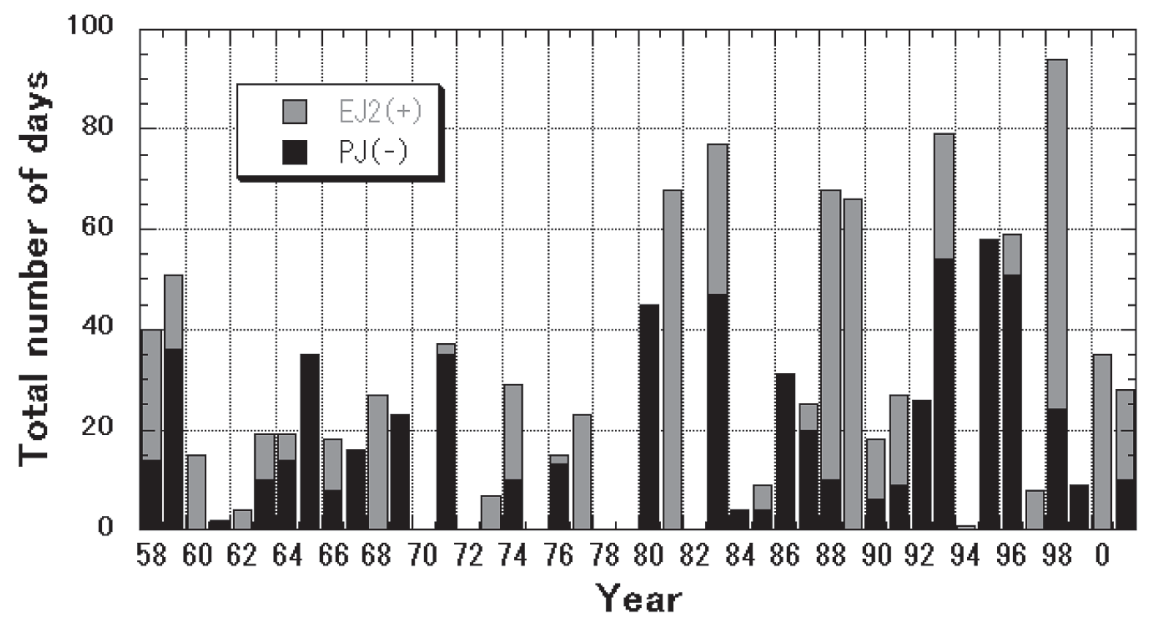

Fig. 12. Total number of days exceeding threshold values of $+1.0 \sigma$ for the LF-EJ2 ${ }^{+}$pattern and $-1.0 \sigma$ for the LF-PJ' pattern during summer.

tern is dominant significantly increases during the post-1980 period. Such an increasing tendency is also valid for the LF-PJ' pattern, which is consistent with the results of Kawamura et al. (1998), who pointed out that large PJ variability is one of the major factors causing severe summers in Korea and Japan after the late 1970s. Since both patterns frequently appear during the post-1980 period, their combination tends to occur, and, as a result, the tripole pattern might have been extracted as the summertime leading mode even though the LF-EJ2 index is almost independent of the LF-PJ one over the whole period. However, another possibility should also be raised, namely, that there is an interaction between the two patterns. As stated earlier, a weak tripole-like pattern is seen in the LF-PJ' $^{-}$composite map (Fig. 2), which might imply that tropical forcing influences an anomalous circulation over the Okhotsk Sea and eastern Siberia through the generation of the LF-PJ pattern. If this is true, the frequent occurrence of the tripole pattern during the post-1980 period may be partly attributed to a larger variability of the LF-PJ pattern in the last two decades. Further investigation of 


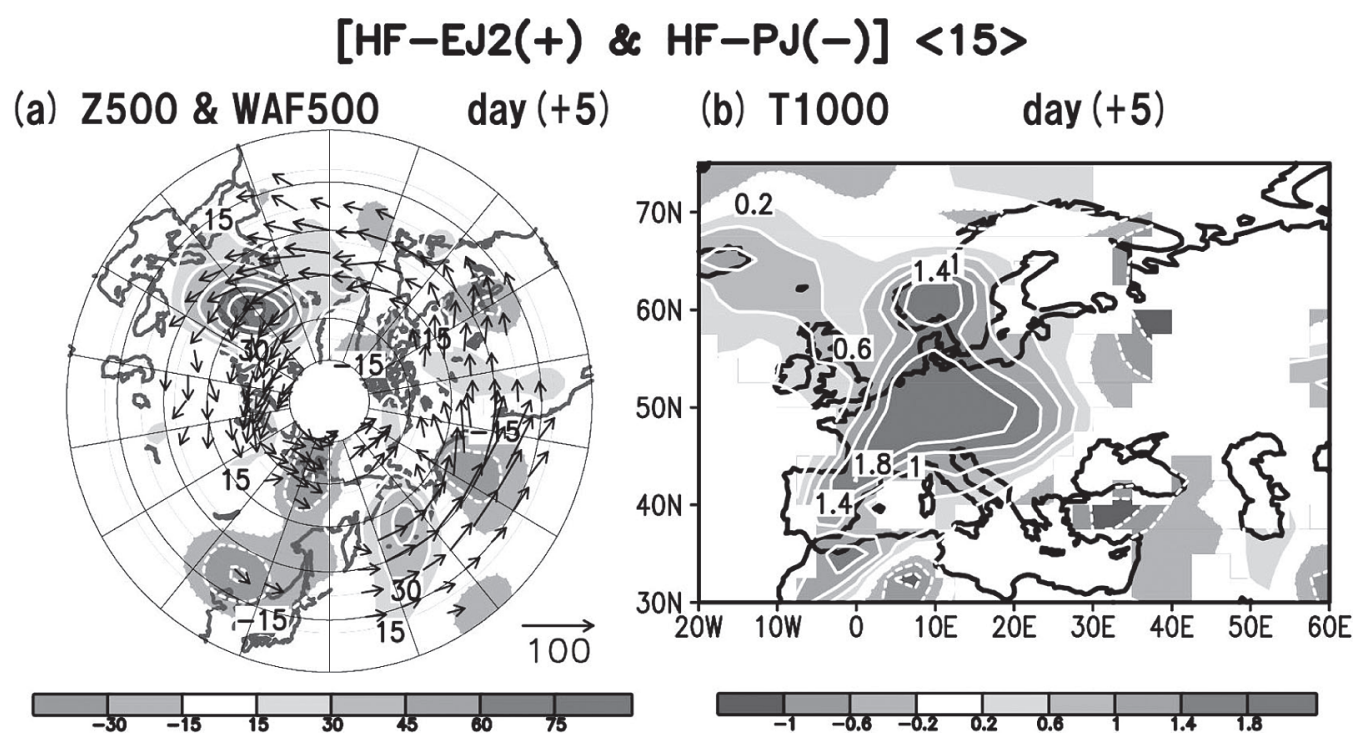

Fig. 13. (a) Composite map of filtered 500-hPa geopotential height anomalies and wave activity fluxes on day +5 for the HF-EJ2 $2^{+} / \mathrm{HF}_{-} \mathrm{PJ}^{-}$combined event. The shading interval for height is $15 \mathrm{~m}$. The reference arrow is $100 \mathrm{~m}^{2} \mathrm{~s}^{-2}$. Fluxes of less than $20 \mathrm{~m}^{2} \mathrm{~s}^{-2}$ are suppressed. (b) As in (a), but for 1000-hPa temperature anomalies. The shading interval for temperature is $0.4^{\circ} \mathrm{C}$.

this issue will be required.

\subsection{A possible linkage between East Asia and Europe}

Although we present composite maps showing the combination of the HF-EJ2 ${ }^{+}$and HF-PJ ${ }^{-}$patterns in Fig. 8, we would like to note a possible linkage between East Asia and Europe in relation to their combination. The left panel of Fig. 13 shows a composite map of filtered $500-\mathrm{hPa}$ geopotential height anomalies in the Northern Hemisphere on day +5 for the combination of the HF$\mathrm{EJ}^{+}$and $\mathrm{HF}-\mathrm{PJ}^{-}$patterns along with wave activity fluxes. In the composite map, a prominent positive anomaly reaches its peak over the vicinity of the Scandinavian Peninsula. This anomaly is already obvious on day +2 (Fig. 8c). Such an anomalous positive height is observed in most of the $15 \mathrm{com}$ bined cases and has a fully statistical significance, whereas, in the $\mathrm{EJ} 2^{+}$and $\mathrm{PJ}^{-}$single cases, there are no distinctive positive anomalies around Europe (not shown). Another difference is the presence of a wavetrain pattern from North Pacific eastward into the North Atlantic in the $\mathrm{EJ} 2^{+} / \mathrm{PJ}^{-}$combined case, accompanied by eastward wave activity fluxes. This feature is not seen in the $\mathrm{EJ}^{+}$and $\mathrm{PJ}^{-}$ single cases. As mentioned in Fig. 8, a new wavetrain pattern develops over North Pacific after day 0 and then dominates across North America, even- tually leading to the establishment of the positive height anomaly over northern Europe. The persistence of the anomalous positive height is expected to increase the summertime surface temperatures. Indeed, a positive $1000-\mathrm{hPa}$ temperature anomaly exceeding $+1.8^{\circ} \mathrm{C}$ covers central Europe on day +5 , as shown in Fig. 13b. It is suggested, thus, that the combination of the HF-EJ $2^{+}$and HF-PJ ${ }^{-}$patterns has a remote and delayed impact on the summertime circulation and associated surface temperature anomalies over Europe via the aforementioned teleconnection. This dynamic process should be considered to properly understand the anomalous summer weather in Europe.

\section{Summary}

In this study, using the European Center for Medium-Range Weather Forecasts (ECMWF) reanalysis (ERA-40) data, we investigated how the combination of two major teleconnection patterns, i.e., the positive EJ2 (EJ2 $2^{+}$pattern and the negative $\mathrm{PJ}\left(\mathrm{PJ}^{-}\right)$pattern, exerts a significant influence on the East Asian summer monsoon variability on sub-monthly (HF) and interannual (LF) timescales. The combination of the LF-EJ2 ${ }^{+}$and LF-PJ ${ }^{-}$patterns induces a noticeable tripole structure in the geopotential height field of the middle troposphere that is characterized by two positive anomalies over the 
Okhotsk Sea and the western North Pacific to the north of the Philippines and a negative anomaly over Japan. In conjunction with such a combination of the teleconnections, another tripole-like pattern is evident in the SST anomaly field of the western North Pacific. The prominence of the LF-EJ2 $2^{+} \mathrm{LF}$ $\mathrm{PJ}^{-}$combination brings about a larger surface temperature decrease, particularly in the northeastern part of East Asia, and a larger SST decrease in the vicinity of Japan than a single teleconnection pattern case, suggesting a substantial impact on the East Asian summer monsoon circulation. Both LF patterns tend to appear frequently during the post-1980 period, and, as a consequence, LFcombined cases may have increased in the last two decades.

The combination of the HF-EJ2 $2^{+}$and HF-PJ ${ }^{-}$patterns also provides a similar tripole structure and results in low-temperature conditions in northern Japan, but one of the significant differences between the HF- and LF-combinations is the time evolutions of positive height anomalies over the Okhotsk Sea. The LF-anomaly tends to stay in almost the same region after the peak day, whereas the HF-anomaly is extremely displaced eastward to the Aleutian Islands a few days after the peak day and occupies part of a newly developed wavetrain pattern across the central North Pacific. Further development of such a wavetrain pattern could be attributed to anomalous convective heating related to enhanced synoptic-scale disturbances to the east of Japan. It is also possible that the stationary Rossby wavetrain pattern across the central North Pacific has a remote and delayed impact on the summertime circulation and surface temperature anomalies over Europe.

We examined the $\mathrm{EJ} 2^{+} / \mathrm{PJ}^{-}$combined cases in this study, but there exist other combined cases, such as $\mathrm{EJ} 2^{+} / \mathrm{PJ}^{+}, \mathrm{EJ} 2^{-} / \mathrm{PJ}^{-}$, and $\mathrm{EJ} 2^{-} / \mathrm{PJ}^{+}$. We need to estimate the relative importance of those cases in terms of their substantial influence on the East Asian summer monsoon circulation, a topic on which we will report in the near future.

\section{Acknowledgments}

Comments by two anonymous reviewers were extremely helpful. This research was supported by the research project "R\&D of hydrological modeling and water resources system" of JST/CREST and by the research project "Refinement of global and regional water cycle" of the Japanese Ministry of Education, Sports, Culture, Science and Tech- nology.

\section{References}

Arai, M. and M. Kimoto, 2006: Simulated interannual variation in summertime atmospheric circulation associated with the East Asian monsoon. Submitted to Geophys. Res. Lett.

Enomoto, T., B.J. Hoskins, and Y. Matsuda, 2003: The formation mechanism of the Bonin high in August. Quart. J. Roy. Meteor. Soc., 129, 157-178.

Ishii, M., A. Shouji, S. Sugimoto, and T. Matsumoto, 2005: Objective analyses of SST and marine meteorological variables for the 20th century using ICOADS and the Kobe collection. Int. J. Climatol., 25, 865-879.

Kanno, H., 2004: Five-year cycle of north-south pressure difference as an index of summer weather in northern Japan from 1982 onwards. J. Meteor. Soc. Japan, 82, 711-724.

Kawamura, R., T. Murakami, and B. Wang, 1996: Tropical and midlatitude 45-day perturbations over the western Pacific during the northern summer. $J$. Meteor. Soc. Japan, 74, 867-890.

Kawamura, R., M. Sugi, T. Kayahara, and N. Sato, 1998: Recent extraordinary cool and hot summers in East Asia simulated by an ensemble climate experiment. J. Meteor. Soc. Japan, 76, 597-617.

Kawamura, R. and T. Ogasawara, 2006: On the role of typhoons in generating PJ teleconnection patterns over the western North Pacific in late summer. SOLA, 2, 37-40.

Krishnan, R. and M. Sugi, 2001: Baiu rainfall variability and associated monsoon teleconnections. $J$. Meteor. Soc. Japan, 79, 851-860.

Lu, R.-Y., J.-H. Oh, and B.-J. Kim, 2002: A teleconnection pattern in upper-level meridional wind over the North African and Eurasian continent in summer. Tellus, 54A, 44-55.

Nakamura, H. and T. Fukamachi, 2004: Evolution and dynamics of summertime blocking over the Far East and the associated surface Okhotsk high. Quart. J. Roy. Meteor. Soc., 130, 1213-1234.

Nitta, T., 1987: Convective activities in the tropical western Pacific and their impact on the Northern Hemisphere summer circulation. J. Meteor. Soc. Japan, 65, 373-390.

Ogasawara, T. and R. Kawamura, 2007: Combined effects of teleconnection patterns on anomalous summer weather in Japan. J. Meteor. Soc. Japan, 85, 11-24.

Sato, N. and M. Takahashi, 2006: Dynamical processes related to the appearance of quasi-stationary waves on the subtropical jet in the midsummer Northern Hemisphere. J. Climate, 19, 1531-1544.

Tachibana, Y., T. Iwamoto, M. Ogi, and Y. Watanabe, 2004: Abnormal meridional temperature gradient 
and its relation to the Okhotsk high. J. Meteor. Soc. Japan, 82, 1399-1415.

Takaya, K. and H. Nakamura, 2001: A formulation of a phase-independent wave-activity flux for stationary and migratory quasigeostrophic eddies on a zonally varying basic flow. J. Atmos. Sci., 58, 608 -627 .

Wakabayashi, S. and R. Kawamura, 2004: Extraction of major teleconnection patterns possibly associated with anomalous summer climate in Japan. $J$. Meteor. Soc. Japan, 82, 1577-1588.

Wang, Y., 1992: Effects of blocking anticyclones in Eurasia in the rainy season (Meiyu/Baiu season). $J$. Meteor. Soc. Japan, 70, 929-950.

Wang, Y. and T. Yasunari, 1994: A diagnostic analysis of the wave train propagating from high-latitudes to low-latitudes in early summer. J. Meteor. Soc. Japan, 72, 269-279.

Wu, R. and B. Wang, 2002: A contrast of the East Asian summer monsoon-ENSO relationship between 1962-77 and 1978-93. J. Climate, 15, 3266-3279.

Yamada, K. and R. Kawamura, 2007: Dynamical link between typhoon activity and the PJ teleconnection pattern from early summer to autumn as revealed by the JRA-25 reanalysis. SOLA, 3, 6568.

Yasunaka, S. and K. Hanawa, 2006: Interannual summer temperature variations over Japan and their relation to large-scale atmospheric circulation field. J. Meteor. Soc. Japan, 84, 641-652. 